\title{
TESTING FOR PESTICIDE RESISTANCE IN LETTUCE APHID
}

\author{
P.J. WORKMAN, M.A.W. STUFKENS, N.A. MARTIN \\ and R.C. BUTLER \\ Crop \& Food Research, Private Bag 4704, Christchurch, New Zealand \\ Corresponding author: workmanp@crop.cri.nz
}

\begin{abstract}
Lettuce aphid, Nasonovia ribisnigri Mosely (Hemiptera: Aphidoidae), was first detected in New Zealand on lettuce (Lactuca sativa) in Christchurch in March 2002. Lettuce growers immediately found the new pest difficult to control using insecticides. Failure of insecticides to provide adequate control could have been due to inadequate spray coverage because lettuce aphid prefers to feed in the interior of the lettuce or to insecticide resistance, which has been recorded in lettuce aphid in Europe. To determine the efficacy of topically applied insecticides on lettuce aphid in New Zealand, 12 pesticides were applied at recommended field rates with a Potter tower to apterous lettuce aphids on lettuce discs imbedded in agar. Only acephate $(80.6 \%)$ and methomyl $(90.7 \%)$ failed to give complete mortality after 48 hours at $18^{\circ} \mathrm{C}$. The concentration-mortality relationships for acephate, methomyl and pirimicarb were estimated and compared with data from Europe.
\end{abstract}

Keywords: lettuce aphid, Nasonovia ribisnigri, lettuce, insecticide resistance.

\section{INTRODUCTION}

Lettuce aphid (Nasonovia ribisnigri) was detected in Christchurch on lettuce in March 2002 and has now spread to all of the main lettuce-growing regions in New Zealand, often as a result of infested lettuce product being distributed within the country (Stufkens $\&$ Teulon 2003). In New Zealand, only five insecticides, acephate, diazinon, methomyl, pirimicarb and pymetrozine, are registered for use on lettuce. Several other insecticides have a general registration for use on vegetables. Many lettuce growers reported that the insecticides they were using were not controlling the new lettuce aphid (Stufkens et al. 2002). In Europe, a number of lettuce aphid populations are resistant to insecticides, including carbamates, organo-phosphates, synthetic pyrethroids and organo-chlorides (Rufingier et al. 1997; Barber et al. 1999).

Other aphid species that damage lettuce crops in New Zealand feed mainly on the outside leaves of the lettuce and are readily controlled by topically applied insecticide sprays. Lettuce aphids prefer to live and feed in the inner leaves and hearts of lettuce where they are protected from topically applied insecticides. It is difficult to determine whether failure of insecticides to control lettuce aphid in the field is due to the resistance of aphids to insecticides, inadequate spray coverage or incorrect choice of pesticide.

This paper examines the effectiveness of 12 insecticides sprayed at field rates directly on to lettuce aphid. It also investigates the concentration-mortality relationships for acephate, methomyl and pirimicarb.

\section{METHOD}

\section{Laboratory testing of pesticides at recommended field rate}

Lettuce aphids were collected from lettuces grown outdoors in Canterbury and reared in the laboratory on insecticide-free lettuces. Leaf discs ( $25 \mathrm{~mm}$ diameter) taken from the inside leaves of Iceberg-type lettuces were embedded in $1 \%$ agar in Petri dishes (10 $\mathrm{mm}$ high, $30 \mathrm{~mm}$ diameter) with a $12 \mathrm{~mm}$ vent in the lids that was covered with fine 
gauze. The agar restricted the aphids to the sprayed surface and supplied moisture to the leaf disk. Five apterous adult or $4^{\text {th }}$ instar nymph lettuce aphids were added to each Petri dish and 10 replicates were used for each insecticide. Each Petri dish with aphids on the leaf surface was opened and sprayed with $2 \mathrm{ml}$ of insecticide with a Potter tower $\left(69 \mathrm{kPa}\right.$.). The Petri dishes were held at $18^{\circ} \mathrm{C}$ (16:8 h light:dark) and numbers of live and dead aphids were assessed after 24 and $48 \mathrm{~h}$. Twelve insecticides (Table 1) were tested plus a water treated control. The concentrations of the insecticides were calculated assuming a water rate of 500 litres/ha.

\section{Concentration-mortality relationships for acephate, methomyl and pirimicarb}

The two pesticides that failed to give complete mortality at field rates, acephate and methomyl, were investigated to estimate levels of resistance in lettuce aphid. The efficacy of these pesticides was also compared with that of pirimicarb. The same bioassay method was used as in the previous field rate tests but six concentrations of each insecticide were tested, including a water control. At each pesticide concentration there were five Petri dishes containing five aphids but some aphids occasionally escaped during the spraying procedure. Mortality was assessed after 48 hours. Each experiment was repeated three times.

\section{Statistical analysis}

Two sets of analyses were carried out. First, the mean \% mortality for each concentration of each pesticide was estimated (along with 95\% confidence intervals). The mean $\%$ mortality for each concentration of each pesticide in each run was also estimated. The change in fit between these models indicated whether the concentrationresponse varied significantly between runs. These models were fitted using a binomial generalised linear model, with a logit link (McCullagh \& Nelder 1989). Secondly, the concentration-mortality curves were estimated in a manner similar to classical probit analysis (Finney 1971), but using a logistic curve of $\log$ (Concentration), allowing for natural mortality:

$$
\% \text { Dead }=\operatorname{Pr} M+\frac{(100-\operatorname{Pr} M)}{1+\left(\frac{\text { Conc }}{L C_{50}}\right)^{b}}
$$

Here, $\operatorname{Pr} M$ is the estimated \% natural mortality, $\mathrm{LC}_{50}$ is the concentration killing half the insects that do not die naturally, and b relates to the steepness of the curve. Curves were fitted allowing $\operatorname{Pr} M$ to vary or be kept the same between runs and chemicals, and allowing $\mathrm{b}$ and $\mathrm{LC}_{50}$ to vary or be kept the same for the different runs of the same pesticide. The fit of the data to the curves was compared to the fit of the data to the means (as above) to test whether there was significant lack of fit of the curves to the means, and thus whether the curves were an adequate description of the concentration response.

All tests were carried out using analysis of deviance (McCullagh \& Nelder 1989), with F-tests of the changes in deviance, and a level of 5\% to determine significance.

The concentration that is estimated to kill $95 \%$ of insects that do not die naturally was calculated from the estimated parameters $\left(\mathrm{LC}_{50}\right.$ and $\left.\mathrm{b}\right)$. Their $95 \%$ confidence limits were estimated from the results of fitting the curves using Fieller's theorem (Finney 1971).

All analyses were carried out using GenStat (GenStat Committee 2002).

\section{RESULTS}

\section{Laboratory testing of insecticides at recommended field rate}

Methomyl and acephate, both registered for use on lettuce, failed to completely kill all of the aphids after 48 hours when they were tested at field rate. All the other insecticides tested gave $100 \%$ control of the lettuce aphid (Table 1). Natural mortality in the water sprayed control was $4.17 \%$. 
TABLE 1: Percentage mortality of lettuce aphid 24 and 48 hours after 12 insecticides were applied at field rate with a Potter tower.

\begin{tabular}{|c|c|c|c|c|c|c|}
\hline \multirow[b]{2}{*}{ Chemical group } & \multirow[b]{2}{*}{$\begin{array}{l}\text { Product } \\
\text { name }\end{array}$} & \multirow[b]{2}{*}{$\begin{array}{l}\text { Common } \\
\text { name }\end{array}$} & \multirow[b]{2}{*}{$\begin{array}{l}\text { Rate of } \\
\text { application }\end{array}$} & \multirow[b]{2}{*}{$\begin{array}{l}\text { Rate (mg } \\
\text { ai/litre) }\end{array}$} & \multicolumn{2}{|c|}{$\%$ Kill } \\
\hline & & & & & $24 \mathrm{~h}$ & $48 \mathrm{~h}$ \\
\hline \multirow[t]{2}{*}{ Carbamate $(\mathrm{Rx})^{1}$} & Pirimor $^{2}$ & pirimicarb & $250 \mathrm{~g} / \mathrm{ha}$ & 250 & 100 & 100 \\
\hline & Lannate $^{2}$ & methomyl & 2 litres/ha & 800 & 81.4 & 90.7 \\
\hline \multirow{4}{*}{$\begin{array}{l}\text { Organo- } \\
\text { phosphate }(\mathrm{Rx})^{1}\end{array}$} & Diazinon $800^{2}$ & diazinon & 1 litre/ha & 1600 & 100 & 100 \\
\hline & Orthene $^{2}$ & acephate & $800 \mathrm{~g} / \mathrm{ha}$ & 1552 & 59.5 & 80.6 \\
\hline & Nuvos & dichlorvos & $800 \mathrm{ml} / \mathrm{ha}$ & 1600 & 96 & 100 \\
\hline & Perfekthion & dimethoate & $800 \mathrm{ml} / \mathrm{ha}$ & 800 & 100 & 100 \\
\hline \multirow{4}{*}{$\begin{array}{l}\text { Synthetic } \\
\text { pyrethroid }(\mathrm{Rx})^{1}\end{array}$} & Karate Zeon & lambda- & $36 \mathrm{ml} / \mathrm{ha}$ & 18 & 100 & 100 \\
\hline & Decis & deltamethrin & $300 \mathrm{ml} / \mathrm{ha}$ & 16.5 & 100 & 100 \\
\hline & Ripcord & cypermethrin & $125 \mathrm{ml} / \mathrm{ha}$ & 50 & 100 & 100 \\
\hline & Fastac alpha & -cypermethrin & $200 \mathrm{ml} / \mathrm{ha}$ & 40 & 100 & 100 \\
\hline Organo-chloride & Thiodan & endosulfan 200 & $\mathrm{ml} / 100$ litres & 700 & 100 & 100 \\
\hline Chloro-nicotinyl & Confidor & imidacloprid & $300 \mathrm{ml} / \mathrm{ha}$ & 210 & 100 & 100 \\
\hline Water control & & & & & 0 & 4.17 \\
\hline
\end{tabular}

${ }^{1}(\mathrm{Rx})=$ Known resistance or partial resistance to the lettuce aphid overseas

${ }^{2}$ Registered for lettuce in New Zealand

\section{Concentration-mortality relationships for acephate, methomyl, and pirimicarb}

There was some minor evidence $(0.05<\mathrm{P}<0.5)$ that the responses varied more between tests than within tests, so standard errors for the fitted curves and confidence limits were based on this between test variability. The overall means for the pesticides are shown in Table 2.

TABLE 2: Mortality (\%) of the three tests for methomyl, acephate and pirimicarb. Values shown are the mean and $95 \%$ confidence intervals (CI).

\begin{tabular}{|c|c|c|c|c|c|c|c|c|}
\hline \multicolumn{3}{|c|}{ Methomyl } & \multicolumn{3}{|c|}{ Acephate } & \multicolumn{3}{|c|}{ Pirimicarb } \\
\hline ppm & Mean & $\mathrm{CI}$ & ppm & Mean & $\mathrm{CI}$ & ppm & Mean & CI \\
\hline 0 & 5.6 & $2.0,14.7$ & 0 & 6.9 & $2.7,16.5$ & 0 & 5.3 & $2.6,10.8$ \\
\hline 50 & 10.8 & $5.2,21.0$ & 194 & 8.1 & $3.5,17.7$ & 16 & 19.3 & $13.5,27.0$ \\
\hline 100 & 14.7 & $8.0,25.4$ & 388 & 32.0 & $21.9,44.1$ & 31 & 44.2 & $36.0,52.6$ \\
\hline 200 & 24.0 & $15.2,35.7$ & 776 & 54.7 & $42.6,66.2$ & 62 & 68.5 & $60.0,75.8$ \\
\hline 400 & 75.0 & $62.9,84.1$ & 1552 & 78.7 & $67.1,86.9$ & 125 & 93.3 & $87.6,96.5$ \\
\hline 800 & 93.2 & $84.0,97.3$ & 3104 & 97.3 & $89.1,99.4$ & 250 & 99.3 & $94.9,99.9$ \\
\hline
\end{tabular}

Natural mortality did not vary significantly between tests, so a single estimate of $6.80 \%$ $(\mathrm{SE}=1.50 \%)$ was used in all calculations. When tested against the between-test variability (dispersion), there was no significant lack of fit between the chemical by rate means and the fitted curves, indicating that the fitted curves were an adequate description of the concentration-mortality response. Parameters for the fitted curves are shown in Table 3.

The analysis of the concentration-mortality relationship confirms the finding in the first experiment that acephate and methomyl did not completely kill lettuce aphid at field rates. The estimated $\mathrm{LC}_{95}$ for both chemicals is higher than the field rate (Table 4). However, while the field rate falls outside the $95 \%$ confidence limits for acephate this is not the case for methomyl. The estimated $\mathrm{LC}_{95}$ and $95 \%$ confidence limits for pirimicarb were lower than the field rate, confirming the effectiveness of this treatment. 
TABLE 3: Estimated parameters, with the SE in parentheses, for the fitted curves for methomyl, acephate and pirimicarb (mg ai/litre).

\begin{tabular}{|c|c|c|c|c|}
\hline Pesticide & \multicolumn{2}{|c|}{$\mathrm{LC}_{50}(\mathrm{SE})$} & \multicolumn{2}{|c|}{$\mathrm{b}(\mathrm{SE})$} \\
\hline Methomyl & 300.3 & $(23.6)$ & 2.752 & $(0.406)$ \\
\hline Acephate & 746.3 & (66.9) & 2.031 & $(0.270)$ \\
\hline Pirimicarb & 39.8 & $(2.6)$ & 2.098 & $(0.197)$ \\
\hline & Natural mo & ality $(\%), \operatorname{Pr} M$ & 6.80 & $(1.50)$ \\
\hline
\end{tabular}

The $\mathrm{LC}_{50}$ and $\mathrm{LC}_{95}$ estimated from these parameters are shown in Table 4.

TABLE 4: Estimated $\mathrm{LC}_{50}$ and $\mathrm{LC}_{95}$ for methomyl, acephate and pirimicarb (mg ai/ litre) compared with field rate.

\begin{tabular}{llrll}
\hline Pesticide & LC $\%$ & \multicolumn{1}{r}{ Concentration } & $(95 \%$ confidence limits $)$ & Field rate \\
\hline \multirow{2}{*}{ Methomyl } & 50 & 300.3 & $(252.9,349.4)$ & \\
& 95 & 875.3 & $(679.1,1344.1)$ & 800 \\
Acephate & 50 & 746.3 & $(616.0,887.3)$ & \\
& 95 & 3180.2 & $(2323.9,5271.6)$ & 1552 \\
Pirimicarb & 50 & 39.8 & $(34.8,45.0)$ & \\
& 95 & 162.2 & $(129.8,220.9)$ & 250 \\
\hline
\end{tabular}

\section{DISCUSSION}

It is surprising that little has been reported on the status of insecticide resistance in lettuce aphid other than 2 European papers, Rafinger et al. (1997) and Barber et al. (1999), as it is an important pest throughout Europe, Central Asia, the Middle East, and North and South America. It is also difficult to determine the insecticide resistance status of the New Zealand populations of lettuce aphid as this pest has only recently arrived in New Zealand and there is no susceptible population with which it can be compared. However, in the laboratory it is possible to identify insecticides that will not completely kill all lettuce aphids present when used at the recommended field rates. Of the 12 pesticides tested, only acephate (organophosphate) and methomyl (carbamate) failed to give $100 \%$ mortality. The other organophoshate and carbamate insecticides gave complete kill rates at field concentrations. As acephate and methomyl fail to achieve $100 \%$ mortality at recommended field rates these chemicals should not be applied to lettuce crops or insecticide resistance may develop amongst lettuce aphids as may cross resistance to other carbamates and organo-phosphates. Pymetrozine, which is registered for use on lettuce, was tested but the results are not included because this type of bioassay, in which mortality is assessed after 48 hours, was not suitable for an insecticide where the mode of action is cessation of feeding and the aphids may take up to 7 days to die.

It is also possible to compare data from investigations into the concentration-mortality relationships for acephate, methomyl and pirimicarb with data from Europe, while recognising the limitations of the comparison due to differences in methodology. Rufingier et al. (1997), using a similar method to those used in these tests, compared four populations of lettuce aphid from the south of France and Spain with a susceptible reference strain (Hol) obtained from the Netherlands where it had been maintained in the absence of insecticides since 1970. A comparison of $\mathrm{LC}_{95}$ data from these European populations with data obtained from New Zealand (Table 5) indicates that the New Zealand population is showing a level of resistance for pirimicarb, methomyl and acephate when compared with the susceptible Netherlands strain. While the $\mathrm{LC}_{95}$ values for the New Zealand population for pirimicarb and methomyl are much lower than those found in the fieldcollected French/Spanish populations, the $\mathrm{LC}_{95}$ value for acephate was within the range found in European populations. 
TABLE 5: $\quad \mathrm{LC}_{95}$ values (mg ai/litre) of $\mathrm{N}$. ribisnigri populations from Europe compared with a New Zealand population.

\begin{tabular}{|c|c|c|c|c|c|c|c|}
\hline & \multicolumn{5}{|c|}{ European populations (Rufingier et al. 1997) } & \multirow[b]{2}{*}{ NZ } & \multirow[b]{2}{*}{ Field rate } \\
\hline & $\mathrm{Hol}^{1}$ & $\operatorname{Par}^{2}$ & $\mathrm{Mas}^{2}$ & $\mathrm{Abr}^{2}$ & Esp $^{3}$ & & \\
\hline Pirimicarb & 34 & 418 & 283 & 2106 & 793 & 162 & 250 \\
\hline Methomyl & 458 & 2487 & 11087 & 20937 & 5038 & 875 & 800 \\
\hline Acephate & 1114 & 10986 & 5360 & 2121 & 4063 & 3180 & 1552 \\
\hline
\end{tabular}

${ }^{1}$ Susceptible population of $N$. ribisnigri from the Netherlands.

${ }^{2} N$. ribisnigri collected from three field samples near Perpignan, south of France.

${ }^{3} \mathrm{~N}$. ribisnigri collected from a field sample near Almeria, Spain.

Barber et al. (1999) used a leaf dip bioassay to compare the susceptibility in lettuce aphid to a range of insecticides. They compared a laboratory strain of lettuce aphid, collected in 1994, with 2 field strains collected from lettuce crops on which pirimicarb had not been effective in Kent and Yorkshire. There was a 7 and 11 fold resistance to pirimicarb in the field strains. They did not test for resistance for acephate or methomyl.

As only 2 of the 12 insecticides tested failed to give complete control of lettuce aphid, failure to obtain control in the field must be mainly due to the preference of lettuce aphids for inhabiting the central leaves of the lettuce where it can avoid pesticides that are topically applied. It will be important when selecting insecticides for lettuce aphid control to match the mode of action, and persistence of the residues, with the growth stage of the plant. Further work is required to determine which insecticides will give the best control of lettuce aphid at different growth stages of the lettuce. Also, insecticides with different modes of action will need to be applied in rotation if insecticide resistance problems are to be minimised.

Since partial insecticide resistance already exists in New Zealand lettuce aphid populations, it would be unwise for growers to depend solely on topical pesticide applications for the control of this pest. The lettuce industry has initiated a project to develop and implement an integrated pest and disease management programme (IPM) for the control of insect pests and plant diseases in outdoor lettuce. One part of this project will aim to identify environmentally sustainable options, including biological control, for the control of lettuce aphid.

\section{ACKNOWLEDGEMENTS}

We gratefully acknowledge Carol Curtis for technical assistance. Funds for this research were provided by Vegfed, MAF Sustainable Farming Fund, and other industry sources.

\section{REFERENCES}

Barber, M.D.; Moores, G.D.; Tatchell, G.M.; Vice, W.E.; Denholm, I. 1999: Insecticide resistance in the currant-lettuce aphid of Nasonovia ribisnigri (Homoptera: Aphididae)in U.K. Bull. Entomol. Res. 89: 17-23.

Finney, D.J. 1971: Probit analysis.Cambridge University Press, Cambridge.

GenStat Committee. 2002: The guide to GenStat release 6.1, Parts 1-3. VSN International, Oxford.

McCullagh, P.; Nelder J.A. 1989: Generalized linear models. Chapman \& Hall, London.

Rufingier, C.; Schoen, L.; Martin, C.; Pasteur, N. 1997: Resistance of Nasonovia ribisnigri (Homoptera:Aphididae) to five insecticides. J. Econ. Entomol. 90(6): 1445-1449.

Stufkens, M.A.W.; Teulon, D.A.J; Bulman, S.R. 2002: Nasonovia ribisnigri a new aphid pest found on lettuces (Lactuca sativa L.) and Ribes spp. in Canterbury. N.Z. Plant Prot. 55: 437.

Stufkens, M.A.W.; Teulon, D.A.J. 2003: Distribution, host range and flight pattern of the lettuce aphid in New Zealand. N.Z. Plant Prot. 56: 27-32. 